\title{
Demographic, Laboratory and Clinical Comparison of Pediatric Brucella Cases with and Without Liver Involvement
}

Mehmet Agin $^{1}$, Yusuf Kayar ${ }^{2}$

${ }^{1}$ Department of Pediatric Gastroenterology, Hepatology and Nutrition, Van Education and Research Hospital, Van, Turkey

${ }^{2}$ Department of Gastroenterology, Van Education and Research Hospital, Van, Turkey

\section{Corresponding Author:}

Mehmet Agin

Department of Pediatric Gastroenterology, Hepatology and Nutrition, Van Education and Research Hospital, Van, Turkey

Telephone: +90-506-801-1083

Fax: 04322175600

Email: drmehmet47@yahoo.com 


\section{ABSTRACT}

Background and Objective: In the present study, the purpose was to compare the demographic, clinical and laboratory results of pediatric brucella cases who had liver involvement and who had no specific organ involvement.

Material and Methods: The data of 248 patients between 2 and 18 years of age diagnosed with Brucellosis between July 2017 and August 2018 were analyzed retrospectively. The patients who had liver involvement and who did not have other specific organ involvement were compared in terms of presentation, physical examination findings, age, gender, hemogram, AST, ALT, GGT, ALP, bilirubines, sedimentation, CRP, clinical and laboratory findings, and culture and relapse rates.

Results: No significant differences were detected between the patients who had liver involvement $(n=92)$ and who did not have specific organ involvement $(n=156)$ in terms of diagnosis age and gender. Loss of appetite, nausea and sensitive stomach were higher in the patients who had hepatic involvement, and weariness was determined to be more in the control group patients. In the patients who had hepatic involvement, the hemoglobin and platelet values were lower, and the sedimentation, CRP and blood culture growth were higher. The relapse rates were lower in patients who had liver involvement.

Conclusion: In patients who have liver involvement, in addition to elevated hepatomegaly and transaminase levels, the growth rate of the acute-phase reactants and brucella is higher in blood culture; and the relapse rate is lower after treatment. Brucellosis must be considered in the differential diagnosis of hepatomegaly and transaminase elevation where brucellosis is seen endemically. We believe that early diagnosis of brucellosis is important in treatment response.

Keywords: brucellosis; elevated liver enzymes; hepatomegaly; children 


\section{Introduction:}

Brucellosis is a disease seen frequently in many parts of the world, particularly in developing countries. It is originally a disease of wild and domestic animals; and is infected to humans during slaughter and during the care of infected animals or by ingesting contaminated meat and milk products of the infected animals. Clinical signs and symptoms of brucellosis are not typical and diagnostic for the disease in humans. The disease may involve many tissues and organs causing various complications [1-3].

Brucellosis is seen endemically in the Arabian Peninsula, India, Mexico, Central and South America and in the Mediterranean countries. It is estimated that there are 500.000 new cases of brucellosis in the world on an annual basis. According to the frequency order in Turkey, it is mostly seen in the Southeastern Anatolia, Central Anatolia, and Eastern Anatolia regions [1].

The majority of the cases become ill in 3-4 weeks after their exposure to active agents [4]. After the infection, they multiply in the regional lymph nodes and pass to the blood. They may involve mostly the reticuloendothelial system, as well as the other systems, and finally cause different clinical manifestations $[5,6]$. Since very different clinical findings may be detected at all ages, the diagnosis is difficult. If it is not treated in a timely and effective manner, chronicity, complications and relapses may be faced [6-8].

During a brucella infection, although the liver is involved almost always, the increase in liver function tests is usually at minimal level. Impairments are detected in liver function tests in approximately $25 \%$ of patients who have acute or chronic brucellosis [9]. Liver and spleen involvements are also detected in approximately 30-60\% of the cases who have brucellosis $[10]$.

Brucellosis is an important and widespread infectious disease in the Eastern Anatolian region of Turkey especially in Van and its surroundings where husbandry is common. In the present study of ours, the purpose was to evaluate and compare the demographic, clinical and laboratory results of children who had brucellosis with liver involvement and without specific organ involvement. 


\section{Material and Methods:}

The data of 248 patients who were between 2 and 18 years of ages and who were diagnosed with brucellosis between July 2017 and August 2018 were analyzed retrospectively. The patients were divided into 2 groups as those who had liver involvement, and those that did not have specific organ involvement. The patients that did not have specific organ involvement were accepted as the Control Group. The patients who had liver involvement and the patients in the Control Group were compared in terms of age, gender, complaints at admission, drinking raw milk and eating fresh cheese, family history of animal husbandry, physical examination findings, laboratory findings, sedimentation, C-Reactive Protein (CRP), treatment, treatment response, relapse rate, and blood culture reproduction. In brucellosis, as the definitive diagnostic criteria, the "Rose Bengal test positivity and Wright agglutination titration being above 1/160" or the "reproduction of Brucella spp. in any culture specimen" were used as well as consistent clinical findings.

Trimethoprim-sulfamethoxazole (10 mg/kg/day), rifampicin $(20 \mathrm{mg} / \mathrm{kg} /$ day $)$ and gentamicin (5-7 $\mathrm{mg} / \mathrm{kg} /$ day) combination was administered to children who were under the age of 8 . Doxycycline (4 mg/kg/day), rifampicin $(20 \mathrm{mg} / \mathrm{kg} / \mathrm{day})$ and Streptomycin $(20 \mathrm{mg} / \mathrm{kg} / \mathrm{day})$ were administered to the children who were older than 8 years. The elevation of sedimentation was evaluated as ESR (erythrocyte sedimentation rate) being above $20 \mathrm{~mm}$ per hour, and the elevation of CRP was evaluated as the serum level of CRP being >5 mg/L. Liver involvement was accepted as; a) Serum alanine transaminase (ALT) > $40 \mathrm{U} / \mathrm{L}$ and serum aspartate aminotransferase (AST) $>40 \mathrm{U} / \mathrm{L}$; b) Palpation of the liver under the ribs in physical examination; and c) Detecting hepatomegaly in abdominal ultrasonography. Granulomatous hepatitis, hepatic abscess, cholecystitis and diffuse hepatitis were considered in abdominal USG.

The patients whose onsets of symptoms were shorter than 8 weeks were evaluated as acute; those between 8-52 weeks were evaluated as subacute; and those that lasted more than 52 weeks were evaluated as chronic. Follow-up was recommended to the patients in the first, third and sixth months and at the first year after the treatment. The patients whose symptoms and signs continued after the treatment were evaluated as unresponsive to the treatment. Having similar complaints and findings at any period in 1 year after the end of the treatment, increase in brucella Standard Agglutination Test (SAT) titer, or Rivanol Brusella standard 
agglutination test result being > 1/160 and/or reproduction in blood culture were accepted as relapse.

\section{Patient informed consent and ethics committee approval}

Verbal and written informed consent was obtained from all the subjects included in the study and from their parents. After the study was completed, the study result of each subject was reported to his/her own parents. Ethics committee approval for the study was given by Van Education and Research Hospital Clinical Research Ethics Committee (Van/Turkey, 01.17.2019-02/2019)

\section{Statistical Analysis}

The normality of distribution of continuous variables was tested by Shaphiro Wilk test. Mann Whitney $\boldsymbol{u}$-test was used to compare 2 independent groups for non-normal data. Chi-square test was applied to investigate the relationship between 2 categorical variables. Statistical analysis was performed with SPSS for Windows version 24.0; and a P value $<0.05$ was accepted as statistically significant.

\section{Results}

In the patients who had liver involvement $(n=92)$ and in the Control Group $(n=156)$, the average age during the diagnosis was $9.5 \pm 4.1$ and $10.3 \pm 4.1$, respectively; and there were no statistically significant differences in this respect. No significant differences were detected between the two groups in terms of gender. In a total of $91 \%$ of the patients who had liver involvement, there was raw milk and fresh cheese intake; $78 \%$ had a family history of animal husbandry; and $31 \%$ had a family history in this respect. In the control group, on the other hand, there was raw milk intake and fresh cheese consumption in 93\%; 80\% dealt with animal husbandry; and $25 \%$ had a family history of brucellosis. No statistically significant differences were detected between the two groups (Table 1).

Among the patients who had liver involvement, a total of $44 \%$ had weariness, $90 \%$ had fever, $50 \%$ had abdominal pain, $88 \%$ had muscle-joint pain, 50\% had abdominal pain, $50 \%$ had nausea, $44 \%$ had loss of appetite, $64 \%$ had sensitive stomach. In the control group, $60 \%$ had fatigue, $90 \%$ had fever, $50 \%$ had abdominal pain, $85 \%$ had muscle-joint pain, $19 \%$ had nausea, loss of appetite in $26 \%$, and $28 \%$ had sensitive stomach. Nausea, loss of appetite, and 
sensitive stomach were determined to be higher in the patients who had liver involvement than in the Control Group $(\mathrm{p}<0.005)($ Table 2).

Hepatomegaly was detected in $48 \%$ of the patients who had liver involvement, splenomegaly was detected in 32\%; and in the Control Group, it was detected in 13\% and splenomegaly in $8 \%$ (Table 2).

The mean hemoglobin and mean platelet counts were lower at a significant level in the liver involvement group when compared to the Control Group, and no significant differences were detected in average white blood cell counts (Table 3).

The AST, ALT, CRP and ESR values were higher in patients who had liver involvement at a significant level compared to the controls; however, no significant differences were detected in terms of total bilirubin, direct bilirubin, albumin, total protein, and alkaline phosphatase (ALP) gamma glutamyl transferase (GGT) (Table 3). Transaminase elevation was higher than 10 times the upper limit of normal in six cases, and was $642 \pm 167$ in AST in average, and $791 \pm 143$ in ALT in average.

Elevated CRP levels were detected in 54\% (138/248) of all the cases that had brucellosis, and $59 \%$ (54/92) of the cases that had liver involvement and 43\% (67/156) of the Control Group had elevated CRP levels. ESR elevation was detected in 38\% (97/248) of all the brucellosis cases, in $77 \%(71 / 92)$ of the cases that had liver involvement, and in $28 \%$ (43/156) of the Control Group (Table 4).

Although the growth rate of the pathogen was 35\% (87/248) in the blood culture in all the brucellosis cases, it was $49 \%$ (45/92) in the cases that had liver involvement, and in $27 \%$ $(42 / 158)$ in the Control Group, and statistically significant differences were detected between the groups $(\mathrm{p}<0.05)$. The relapse rates were $15 \%(36 / 248)$ in all the brucellosis cases, $9 \%$ $(8 / 92)$ in the cases that had liver involvement, and 18\% (28/156) in the Control Group. Statistically, it was determined to be lower at a significant level in the cases that had liver involvement (Table 4).

\section{Discussion:}

No significant differences were detected between the cases that had liver involvement $(n=92)$ and the Control Group $(n=156)$ in terms of age and gender. In children, 50\% of the childhood brucellosis cases are acute, and the rest are subacute or subclinical [8]. In our study, the 
average complaint duration was $21.5 \pm 17.2$ days in all the cases that had brucellosis, 21.6 \pm 17.6 days in the cases that had liver involvement, and 21.2 \pm 17.1 in the Control Group. A total of $72 \%$ of the cases were acute, and $28 \%$ were subacute brucellosis. No correlations were detected between liver involvement and average duration of complaints. We believe that higher acute brucellosis cases might be because of the awareness on the symptoms of brucellosis in people living in the endemic area. As brucellosis can involve different organs and systems, it may present with different symptoms and findings. Fever, weariness, loss of appetite and nausea were the most common complaints in all our cases that had brucellosis. In patients that had liver involvement, loss of appetite, nausea and sensitive stomach were more frequent; however, the Control Group had more weariness. Similar to our study, it was reported in previous studies that fever, weariness, loss of appetite and nausea were the most common complaints of brucellosis at admission.

In $91 \%$ of our brucellosis cases, there was a history of consuming raw milk and raw cheese, and dealing with animal husbandry in $80 \%$. No significant differences were detected between the patients that had and that did not have liver involvement in terms of consuming raw milk and fresh cheese and dealing with animal husbandry in the family. It was reported in previous studies that consuming raw milk and fresh cheese was between 53-91\% [11-15]. Animal contact or family history in animal husbandry were reported between $15-50 \%$ in previous studies $[11-13,16]$. In the present study of ours, similar rates were obtained in both groups.

In previous studies conducted in our country or abroad, family history of brucellosis was reported as 9\% - 50.9\% [17-19]. In studies conducted in Turkey it was reported to be 3\% - 33\% $[11,16]$. In our study; however, this rate was seen in $35 \%$ of the patients that had brucellosis, $31 \%$ in patients that had liver involvement, and $25 \%$ in the Control Group. This supports the arguments that brucellosis may be usually associated with milk and dairy products that are consumed commonly, and we believe that the history may be a diagnostic clue.

Liver involvement is frequently detected in brucellosis. In brucellosis cases, liver involvement is seen in the form of diffuse hepatitis, granulomatous hepatitis, and rarely, hepatic brucelloma [10]. Sometimes, hepatotoxicity may be experienced due to the medication administered; however, this is rarely seen at a rate of 2-3\% of cases [21-23]. Hepatomegaly was reported at a rate of between $4.6 \%$ and $63 \%$ in previous studies [13, 15, 16, 22, 24, 25]. In our study, too, it was detected in $25 \%$ of all the cases that had brucellosis, in $48 \%$ in the cases that had liver involvement, and in $13 \%$ in the Control Group, which is in accordance 
with the literature. Statistically significant differences were detected between the two groups. As brucellosis is an infection that involves mainly RES, spleen involvement is also seen in infection. In previous studies, spleen size was reported to be between $6.7-33 \%$ [11-13, 17]. In our study, when all the cases with brucellosis were evaluated, splenomegaly was detected in $17 \%$ of all the cases, in $32 \%$ of the cases that had liver involvement, and in $8 \%$ in the Control Group. It was significantly higher in the group that had liver involvement. Hepatomegaly and splenomegaly vary according to the severity of the disease, whether it is chronic or not, and to the presence of primary involvement in the related organs. Brucellosis is a disease that may cause liver damage by affecting RES, but has a high response rate to the treatment. However, no pathologies were detected in our study about the liver parenchyma with ultrasonography in our cases.

ESR, CRP and transaminases are among the non-specific laboratory tests that are employed in diagnosis. Acute phase reactants generally increase moderately in brucellosis cases [6, 27]. One of the usage areas of ESR is the diagnosis and follow-up of infectious diseases [28]. In previous studies, ESR elevation was reported as between 49-72\% [11-13, 16, 25]. In our study, it was detected in $38 \%$ of all the cases that had brucellosis, in $59 \%$ of the cases that had liver involvement, and in $28 \%$ of the cases in the Control Group. Significant differences were detected between the two groups.

CRP is among the first increasing acute phase reactants in inflammatory diseases, and is also employed in evaluating the disease activity [29]. It was reported in previous studies that CRP was between $40-72 \%[11,13,16,25]$. In our study, it was detected in $54 \%$ of all the patients that had brucellosis, in $77 \%$ of the cases that had liver involvement, and in $43 \%$ of the cases in the Control Group. Significant differences were detected between the two groups.

Increase in liver enzymes is observed in brucellosis because of granulomatous or non-specific hepatitis [30]. It was reported in previous studies that transaminase elevation is between $17.3 \%$ and $45.6 \%$ in patients that have brucellosis $[11-13,16]$. In our study, it was detected in $37 \%$ of all the brucellosis cases. Our data are consistent with the values that are reported in the literature.

The diagnosis is made in brucellosis by detecting positivity in serological tests and/or producing the agent in the blood [6]. The agglutination in the tube test (Wright), slide agglutination test (Rose Bengal), Complement Fixation test and ELISA are used for this purpose $[4,6]$. In our cases, antibody titers ranged between 1/160 and 1/3840. 
The production of the agent in brucellosis patients ensures the definite diagnosis $[4,5,31]$. In different studies, the reproduction of the active agent in children who had brucellosis varied between $23.5 \%$ and $59.7 \%$ [2, 11, 14, 16, 31, 32]. Brucella spp. reproduced in $35 \%$ of all brucellosis patients in our study. It reproduced in $49 \%$ of the patients that had liver involvement and in $27 \%$ of the patients in the Control Group. Since the most reliable factor is blood culture in diagnosis, blood culture must be sent for all cases that are suspected to have brucellosis.

The detection of the correlation between blood culture positivity and elevated liver enzymes, and CRP and ESR levels were considered to be consistent with the fact that brucellosis is a pathogen that involves RES.

The main purpose of the treatment in brucellosis is both controlling the acute disease and preventing complications and relapses. As clinical relapses can be seen in brucellosis after a treatment with a single antibiotic, it is not recommended $[33,34]$. The cure rate was $89.1 \%$ in 6 weeks of treatment in children, and $95.5 \%$ in eight weeks of treatment. However, the generally accepted treatment duration is six weeks [35]. The relapse rates after 6 weeks of treatment reported in the literature range between $5 \%$ and $12 \%[11,35]$. Our cases were treated in line with the treatment recommendations for childhood; and after six weeks of treatment, the relapse rates were; $9 \%$ in the liver involvement group, and $18 \%$ in the Control Group.

As a result, importance must be given on education and preventive studies especially in endemic areas because of the lack of specific clinical findings for childhood brucellosis, the occurrence of complications, loss of labor force, and because of its ability to affect large masses. In addition to high hepatomegaly and transaminase levels, the growth rates of acute phase reactants and brucella are higher in blood culture in patients who have liver involvement and the relapse rates are lower after the treatment. We believe that brucellosis must be kept in mind in the differential diagnosis of transaminase elevation and acute hepatitis in areas where brucella is endemic; and early diagnosis is important for the response to treatment.

\section{References}


1.Young EJ.Brucella species.In:Mandell GL, Bennett JE, Dolin R (eds).Principles and Practice of Infectious Diseases. $5^{\text {th }}$ ed. Philadelphia: Churchill Livingstone, 2000:2386-92.

2. Gur A, Geyik MF, Dikici B, et al. Complication of brucellosis in different age groups: A study of 283 cases in Southeastern Anatolia of Turkey. Yonsei Med J 2003; 44: 33-44.

3.Colmenero JD, Reguera JM, Martos F, et al. Complications associated with Brucella melitensis infection: A study of 530 cases. Med 1996;75:195-211

4. American Academy of Pediatrics. Brucellosis. In:Pickering LK, editörs. 2009 Red Book: Report of the Committee on Infectious Diseases. 28th ed. Elk Grove Village, IL: American Academy of Pediatrics 2009: 237-9.

5. Young EJ. Brucellosis. In: Feigin RD, Cherry JD (eds). Textbook of Pediatric Infectious Diseases. Fifth edition. Philedelphia: 6th ed.WB Saunders Company, 2009, 1678-82.

6. Yılmaz K, Bayraktaroğlu Z, Sivaslı E, ve ark. Bruselloz tanılı çocuk hastalarda klinik ve laboratuvar verilerinin değerlendirilmesi. Çocuk Dergisi 2004; 4: 102-6.

7. Schutze GE, Jacobs RF. Brucella. In: Behrman RE, Kliegman RM,Jenson HB, editors: Nelson Textbook of Pediatrics 18th ed. Philadelphia: W.B. Saunders Company 2007, 1214-6.

8. Vardar F, Gökşen D, Kurugül Z, Özkınay F. Bruselloz Tanı ve Sağaltımı. Ege Pediatri Bülteni 2000; 7: 29-32.

9. Black FT. Brucellosis. In: Armstrong D, Cohen J, eds. Infectious Diseases. Vol 2. London: Mosby, 1999: 6.34.15-7.

10. Pappas G, Papadimitriou P, Akritidis N, Christou L, Tsianos EV. The new global map of human brucellosis. Lancet Infect Dis 2006;6:91.

11. Eda Karadağ-Öncel, Yasemin Özsürekci, Ali Bülent Cengiz, Ateş Kara, Mehmet Ceyhan, Melda Çelik, Aslınur Özkaya-Parlakay. Çocukluk çağında bruselloz: Hacettepe Üniversitesi Deneyimi. Çocuk Sağlı̆̆ 6

ve Hastalıkları Dergisi 2011; 54: 135-141

12. Helvaci M, Dincer A, Barisik V. The Retretrospective Evaluation of 57 Cases with Brucellosıs in Chıldhood.Tepecik Eğit Hast Derg 2011; 21 (3): 135-8

13.Abuhandan M, Guzel B, Cakmak A, Cicek A. Pediatric Brucellosis:A Retrospective Evaluation of 82 Cases. J.Pediatr Inf 2012;6:74-8

14. Shaalan MA, Memish ZA, Mahmoud SA, Alamari A, Khan MY, Almuneef M, et al. Brucellosis in children: clinical observations in 115 cases. Int J Dis 2002; 6 (3): 182-6.

15. Benjamin B, Khan MRH. Hip Involvement in Childhood Brucellosis. J Bone Joint Surg 1994; 76-B: 544-7. 
16.Celebi S, Hacimustafaoglu M, Demirtas F, Sali E, Gul U, Ozel M. Brucellosis in Childhood. J Pediatr Inf 2011;5:59-62

17. Tanir G, Tufekci SB, Tuygun N. Presentation,complications, and treatment outcome of brucellosis in Turkish children. Pediatr Int 2009; 51: 114-119.

18. Wallach JC, Miguel SE, Baldi PC, Guarnera E, Goldbaum FA, Fossati CA. Urban outbreak of a Brucella melitensis infection in an Argentine family: clinical and diagnostic aspects. FEMS Immunol Med Microbiol 1994; 8: 49-56.

19. Abramson O, Rosenvasser Z, Block C, Dagan R.Detection and treatment of brucellosis by screening a population at risk. Pediatr Infect Dis J 1991; 10:434-438.

20. Young EJ, Hasanjani Roushan MR, Shafae S, Genta RM, Taylor SL. Liver histology of acute brucellosis caused by Brucella melitensis. Hum Pathol 2014;10: 2023-8.

21. Buzgan T, Karahocagil MK, Irmak H, Baran AI, Karsen H, Evirgen O, et al. Clinical manifestations and complications in 1028 cases of brucellosis: A retrospective evaluation and review of the literature. Int J Infect Dis 2010;6:11.

22. Demiroglu YZ, Turunc T, Aliskan H, Colakoglu S, Arslan H. Brucellosis: Retrospective evaluation of the clinical, laboratory and epidemiological features of 151 cases. Mikrobiyol Bul 2007;4:517-27.

23. Akritidis N, Tzivras M, Delladetsima I, Stefanaki S, Moutsopoulos HM, Pappas G. The liver in brucellosis. Clin Gastroenterol Hepatol 2007;9:1109-12.

24. Ozturk Engin D, Erdem H, Gencer S, Kaya S, Baran AI, Batirel A, et al. Liver involvement in patients with brucellosis: Results of the Marmara study. Eur J Clin Microbiol Infect Dis 2014;7:1253-62.

25. E. Doyuk-Kartal, İ. Ozguneş, H. Çolak, G. Usluer. Evaluation of 68 brucellosis cases a7ccording to system involvement. Flora Derg, 9 (2004), pp. 258-265

26. Alsubaie S, Almuneef M, Alshaalan M, et al. Acute brucellosis in Saudi families: relationship between brucella serology and clinical symptoms. Int J Infect Dis 2005; 9: 218224.

27. Galanakis E, Bourantis KL, Leveidiotou S, Lapatsanis PD. Childhood brucellosis in north- western Greece: a retrospective analysis. Eur J Pediatr 1996; 155: 1-6.

28. Plebani M, Piva E. Erythrocyte sedimentation rate. Am J Clin Pathol. 2002;117:621-6.

29. Johnson AM, Rohlfs EM, Silverman LM. Proteinler (çeviri: S. Demir). Arslan D, ed. Klinik Kimyada Temel İlkeler, Palme Yayıncılık, Ankara, 2005:325-51. 
30. Dilek İ, Durmuş A, Karahocagil MA, Akdeniz H, Karsen H, Baran Aİ, Evirgen Ö. Hematological complications in 787 cases of acute brucellosis in eastern Turkey. Turk J Med Sci. 2008;38:421-4.

31. Issa H, Jamal M. Brucellosis in Children in South Jordan. East Med Health J 1999; 5: 895-902.

32. Mantur BG, Akki AS, Mangalgi SS, Patil SV, Gobbur RH, Peeropur BV. Childhood brucellosis-a microbiological, epidemiological and clinical study. J Trop Pediatr 2004; 50: 153-7.

33. Ariza J, Gudiol F, Pallares R, Viladrich PF, Rufi G, Corredoira J. Treatment of human brucellosis with doxycycline plus rifampin or doxycycline plus streptomycin: a randomized, double-blind study. Ann Intern Med 1992; 117: 25-30.

34. Agalar C, Usubutun S, Turkyilmaz R. Ciprofloxacin and rifampicin versus doxycycline and rifampicin in the treatment of brucellosis. Eur J Clin Microbiol Infect Dis 1999; 18: 535538.

35. Roushan MR, Mohraz M, Janmohammadi N, Hajiahmadi M. Efficacy of cotrimoxazole and rifampin for 6 or 8 weeks of therapy in childhood brucellosis. Pediatr Infect Dis J 2006; 25: 544-545.

Disclosure statements: The authors declare no conflicts of interest.

Acknowledgements: The authors declare that this study has received no financial support.

Authorship contribution: M.A. and Y.K. developed the study protocol, screened and enrolled the patients, assessed the outcomes, preliminarily analyzed the data, and wrote the manuscript. M.A. and Y.K. developed the study protocol and analytical framework for the study and contributed to the writing of the manuscript. M.A. screened the patients. M.A and Y.K supervised the design and execution of the study, performed the final data analyses, and contributed to the writing of the manuscript. All the authors have read and approved the final manuscript. 
Table 1: Comparison of the demographic data of the groups

\begin{tabular}{|l|c|c|c|c|}
\hline & \multicolumn{3}{|c|}{ Liver involvement } \\
\hline Variables & Yes & No & Total \\
& $(\mathrm{N}=92)(\mathrm{n} ; \%)$ & $(\mathrm{N}=156)(\mathrm{n} ; \%)$ & $(\mathrm{N}=248)(\mathrm{n} ; \%)$ \\
\hline Diagnosis age & $9.5 \pm 4.1$ & $10.4 \pm 4.1$ & $9.9 \pm 3.9$ & 0.194 \\
\hline Raw milk and fresh chees & $82(\% 92)$ & $144(\% 93)$ & $226(\% 91)$ & 0.613 \\
\hline intake & & & & 0.805 \\
\hline Animal husbandry & $71(\% 78)$ & $123(\% 79)$ & $194(\% 78)$ & 0.285 \\
\hline
\end{tabular}


Table 2: Comparison of symptoms and physical examination findings of the groups

\begin{tabular}{|l|c|c|c|c|}
\hline & \multicolumn{2}{|c|}{ Liver involvement } & \\
\hline & Yes (N=92) (n;\%) & No (N=156) (n;\%) & Total (N=248) (n;\%) & $P$ \\
\hline Temperature & $83(\% 90)$ & $140(\% 90)$ & $223(\% 90)$ & 0.949 \\
\hline puscle and joint & $75(\% 82)$ & $131(\% 85)$ & $202(\% 83)$ & 0.541 \\
\hline Weariness & & & & 0.012 \\
\hline Stomach ache & $45(\% 40)$ & $93(\% 60)$ & $133(\% 54)$ & 0.950 \\
\hline Nausea & $48(\% 52)$ & $29(\% 19)$ & $121(\% 49)$ & 0.001 \\
\hline Lack of appetite & $40(\% 44)$ & $41(\% 26)$ & $81(\% 31)$ & 0.005 \\
\hline Sensitive stomach & $59(\% 64)$ & $44(\% 28)$ & $103(\% 42)$ & 0.001 \\
\hline Hepatomegaly & $44(\% 48)$ & $20(\% 13)$ & $64(\% 26)$ & 0.001 \\
\hline Splenomegaly & $30(\% 33)$ & $12(\% 8)$ & $42(\% 17)$ & 0.001 \\
\hline
\end{tabular}


Table 3: Comparison of the laboratory values of the groups

\begin{tabular}{|l|l|l|l|}
\hline & \multicolumn{2}{|c|}{ Liver involvement } & \\
\hline Variables & Yes & Non & P \\
\hline White cell, mm ${ }^{3}$ & $8522 \pm 8853$ & $7735 \pm 3156$ & 0.954 \\
\hline Hemoglobin, g/dl & $11.6 \pm 1.4$ & $13 \pm 2.6$ & 0.001 \\
\hline Thrombocyte, mm ${ }^{3}$ & $251531 \pm 104728$ & $295948 \pm 94967$ & 0.001 \\
\hline AST, IU/L & $139 \pm 158$ & $24 \pm 10$ & 0.001 \\
\hline ALT, IU/L & $162 \pm 201$ & $20 \pm 9$ & 0.001 \\
\hline Total bilirubin, mg/dl & $0.4 \pm 0.2$ & $0.4 \pm 0.1$ & 0.897 \\
\hline Direct bilirubin, mg/dl & $0.1 \pm 0.2$ & $0.1 \pm 0.1$ & 0.911 \\
\hline Albumin, g/dl & $3.6 \pm 1.2$ & $3.7 \pm 1.1$ & 0,960 \\
\hline $\begin{array}{l}\text { Alkaline phosphatase, } \\
\text { IU/L }\end{array}$ & $113 \pm 78$ & $120 \pm 75$ & 0.871 \\
\hline GGT, IU/L & & & \\
\hline CRP, mg/L & $66 \pm 23$ & $65 \pm 18$ & 0.891 \\
\hline ESR, mm/h & $34 \pm 28$ & $10.4 \pm 17$ & 0.001 \\
\hline
\end{tabular}


Table 4: Comparison of infection parameters and relapse rates of the groups

\begin{tabular}{|l|c|c|c|c|}
\hline & \multicolumn{2}{|c|}{ Liver involvement } & Total & \\
\hline Variables & $\operatorname{Var}(\mathrm{N}=92)(\mathrm{n} ; \%)$ & Yok (N=156) (n;\%) & $\mathrm{N}=248(\mathrm{n} ; \%)$ & $\mathrm{p}$ \\
\hline CRP, mg/L & $54(\% 59)$ & $67(\% 43)$ & $121(\% 49)$ & 0.001 \\
\hline ESR, mm/h & $71(\% 77)$ & $43(\% 28)$ & $114(\% 46)$ & 0.001 \\
\hline $\begin{array}{l}\text { Blood culture } \\
\text { reproduction }\end{array}$ & $45(\% 49)$ & $42(\% 27)$ & $87(\% 35)$ & 0.001 \\
\hline Relapse & & & & 0.046 \\
\hline
\end{tabular}

